EPiC Series in Engineering
Volume 3, 2018, Pages 117-122
HIC 2018. 13th International
Conference on Hydroinformatics

\title{
Model Predictive Control of Salinity and Water Level in a Hypothetical Polder Ditch: Is it Possible to Use the Discretized Linearized Physical Equations for Optimization
}

\author{
Boran Ekin Aydin ${ }^{1 *}$, Martine Rutten ${ }^{1}$, Edo Abraham ${ }^{1}$ \\ ${ }^{1}$ Department of Water Management, Delft University of Technology, 2628CN, Delft, The \\ Netherlands \\ b.e.aydin@tudelft.nl
}

\begin{abstract}
Surface water salinization in deltaic areas due to saline groundwater exfiltration is an important issue. Fresh water diverted from the rivers is used for flushing the canals and the ditches in coastal areas to remove the low quality saline surface water mixed with saline groundwater. Worldwide, deltaic areas are under stress due to climate change, sea level increase and decrease in fresh water availability. The current fresh water management strategies in polders to overcome the salinization problem solely depends on uncontrolled freshwater use. However, this operation will not be effective during a scarce freshwater availability scenario and has to be revised for efficient management possibilities. With the advances in real time measurement of salinity and water level measurements, using a Model Predictive Control (MPC) scheme for the operation of a polder system is gaining popularity. MPC is a powerful control tool that can handle multiple objectives, consider the constraints and the uncertainties of the system. However, a MPC scheme requires a simple and reliable internal model that will be used to calculate the optimum control actions. The internal model should be robust, should reflect the system behaviour with enough detail and should not be computationally costly. In this paper, a MPC scheme is proposed using the discretized linearized De Saint Venant (SV) and Advection-Diffusion (AD) equations as the internal model of the controller. The proposed scheme will be able to control salinity and water level at any discretization point by manipulating the flushing and outflow discharges. This is an ongoing research with tests continuing on a realistic test case.
\end{abstract}

${ }^{*}$ Corresponding author 


\section{Introduction}

In low-lying deltaic areas such as; Mississippi delta in Louisiana (USA), the Ganges-Brahmaputra delta (Bangladesh), or the Rhine-Meuse delta (Netherlands), saline groundwater will increasingly move towards the ground surface and exfiltration to surface water (Delsman, 2005). Due to the salinization of the surface water, it will be less appropriate for agricultural and industrial use and drinking water production. In order to satisfy the irrigation water demands of the farmers with certain quality requirements, freshwater diverted from rivers is used for flushing the canals and ditches in coastal areas. In Netherlands, flushing operations covers $15 \%$ of the total freshwater (Klijn et al., 2012). The demand is expected to increase with the expected increase of surface water salinization (Oude Essink et al., 2010). Therefore, an efficient way for operation of polder systems is necessary.

Model Predictive Control. (MPC) is used for controlling water quality and quantity in the literature (Xu et al., 2010, 2013 and Aydin et al., 2016) with different internal models. In this paper, we will formulate an internal model for the MPC to control salinity and water level using the discretised and linearized De Saint Venant (SV) and Advection Diffusion (AD) equations. A time variant state space description and the objective function formulation will be provided. The related information will be provided by using a hypothetical polder ditch.

\subsection{Polders}

Polders are low-lying and artificially drained areas that are surrounded by dikes. Weirs or sluices are used in polders to connect water courses or ditches in polders (Xu et al., 2010). To avoid dike failures, keeping the water levels in polders and surrounding storage canals within a given margin has high importance. Moreover, the salinity of polder water determines the possibility of using the available water for irrigation purposes. These two objectives have to be kept within the prescribed ranges for successful operation of the polder system.

\subsection{Model Predictive Control}

MPC is an optimization based control strategy which uses a process model to predict the future process outputs within a specified prediction horizon (Camacho and Bordons, 2007). An internal model, which has to be sufficiently accurate to represent the actual system (Camacho and Bordons, 2007), is used to predict the future states and control actions. At each time step, an open loop optimal control sequence is calculated by solving an optimization problem. Only the first element of this sequence is applied to the system and the rest is discarded.

\subsection{System Dynamics and Equations}

In a polder system, for solving the salinity and water level control problem water movement and dissolved salt transport has to be considered and can be modelled by using SV and AD equations respectively. These equations are linearized and discretised in (Xu et al., 2013, 2010) and will not be repeated here for the sake of simplicity. We will use these equations for the simulation and internal model design for the controller. 


\subsection{Test Polder Ditch}

To describe the controller design, we will introduce a hypothetical polder ditch (Figure 1) with concentrations and discharges of $C_{\text {flush}}, Q_{\text {flush }}$ (for flushing), $C_{\text {out }}, Q_{\text {out }}$ (for outflow) and $C_{\text {exf }}, q_{\text {exf }}$ (for saline groundwater exfiltration).

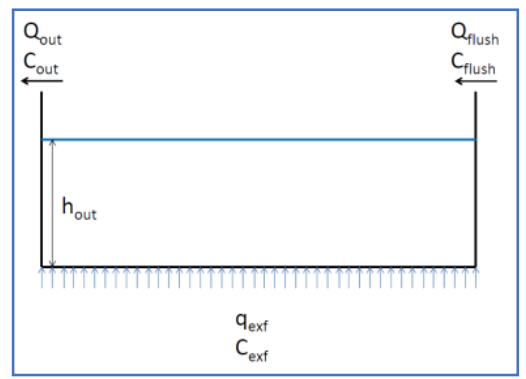

Figure 1: Hypothetical Polder Ditch

\section{Controller Design}

The objective of the controller is to control the salinity $\left(C_{\text {out }}\right)$ and water level $\left(h_{\text {out }}\right)$ at the end of the ditch (Figure 1) which will be represented by the last discretization point of the discretization scheme given in (Xu et al., 2013) by manipulating the change of flushing $\left(Q_{\text {flush }}\right)$ and outflow $\left(Q_{\text {out }}\right)$ discharges. In this study, we will focus on the possibility of using the linearized SV and AD equations as an internal model for a MPC scheme to control salinity and water level. A time variant state space description for a MPC scheme is given in equation 1.

$$
x(\mathrm{k}+1)=A(\mathrm{k}) x(\mathrm{k})+B(\mathrm{k}) u(\mathrm{k})+B_{d}(\mathrm{k}) d(\mathrm{k})
$$

Where $x$ is the state vector of the system $\left(\mathrm{h}_{\mathrm{i}}, \mathrm{c}_{\mathrm{i}}(\mathrm{i}=1: \mathrm{n}), Q_{\mathrm{flush}}, Q_{\text {out }}\right), u$ is the controlled variable ( $\Delta Q_{\text {flush }}, \Delta Q_{\text {out }}$ ), $d$ is the disturbance and $k$ is the time step index. $A, B$ and $B_{d}$ are the matrices associated with system states, control input and disturbance input respectively. $\mathrm{n}$ is the number of discretization points used in the discretization scheme.

\subsection{Discretization Matrices}

A combined discretization matrix including the control variables will be provided here. To illustrate how the matrix will look, we demonstrate a system with 3 discretization points (Eqn 2). All the terms with the next time step $(\mathrm{k}+1)$ are written on the left side and the terms with the current time step $(\mathrm{k})$ are left on the right side such that the state, controlled variables and the disturbances in equation 1 is also present in discretization matrix. 


$$
\begin{aligned}
& {\left[\begin{array}{lllllll}
s v_{11} & s v_{12} & & & & & \\
s v_{21} & s v_{22} & s v_{23} & & & & \\
& s v_{32} & s v_{33} & & & & \\
& & & a d_{11} & a d_{12} & & \\
& & & a d_{21} & a d_{22} & a d_{23} & \\
& & & & a d_{32} & a d_{33} & \\
& & & & 1 & \\
& & & & & 1
\end{array}\right]^{k+1}\left[\begin{array}{c}
h_{1} \\
h_{2} \\
h_{3} \\
c_{1} \\
c_{2} \\
c_{3} \\
Q_{\text {flush }} \\
Q_{\text {out }}
\end{array}\right]^{k+1}=} \\
& {\left[\begin{array}{ccccccc}
s v_{11} & s v_{12} & & & & & \\
s v_{21} & s v_{22} & s v_{23} & & & & \\
& s v_{32} & s v_{33} & & & & \\
& & & a d_{11} & a d_{12} & & \\
& & & a d_{21} & a d_{22} & a d_{23} & \\
& & & a d_{32} & a d_{33} & \\
& & & & 1 & \\
& & & & 1
\end{array}\right]^{k}\left[\begin{array}{c}
h_{1} \\
h_{2} \\
h_{3} \\
c_{1} \\
c_{2} \\
c_{3} \\
Q_{\text {flush }} \\
Q_{\text {out }}
\end{array}\right]^{k}+\left[\begin{array}{c}
\Delta Q_{\text {flush }} \\
\Delta Q_{\text {out }}
\end{array}\right]^{k+1}+[I][d]^{k}}
\end{aligned}
$$

\subsection{Internal Model and the State Space Description}

By multiplying equation 2 by the inverse of the first matrix on the left side of the equation 2 , the state space description given in equation 1 is obtained and can be used for the optimization of the MPC.

\subsection{Forward Estimation}

The state space description given in equation 1 is time variant. Therefore, every time step the matrices associated with the states, inputs and disturbances have to be updated. To achieve that a forward estimation procedure is applied to pre-simulate the system using the previous time steps control flows to get an estimate of the time variant elements of state space description.

\subsection{Objective Function}

To find the optimum control actions, an objective function is solved over the prediction horizon. To minimize the deviation from the set points of water level (sph) and concentration (spc) the states are replaced by error terms. The objective function is given in equation 3. $\mathrm{Q}_{\mathrm{eh}}, \mathrm{Q}_{\mathrm{ec}}, \mathrm{R}_{\Delta \mathrm{Qflush}}, \mathrm{R}_{\Delta \mathrm{Qout}}$ are the weights that panelises the deviations of states from set points and change of flows. 


$$
\begin{aligned}
& \min J=\sum_{i=0}^{n}\left\{e_{h}(k+i \mid k) Q_{e_{h}} e_{h}(k+i \mid k)+e_{c}(k+i \mid k) Q_{e_{c}} e_{c}(k+i \mid k)\right\} \\
& +\sum_{i=0}^{n-1}\left\{\Delta Q_{\text {flush }}(k+i \mid k) R_{\Delta Q_{\text {flush }}} \Delta Q_{\text {flush }}(k+i \mid k)+\Delta Q_{\text {out }}(k+i \mid k) R_{\Delta Q_{\text {out }}} \Delta Q_{\text {out }}(k+i \mid k)\right\}
\end{aligned}
$$

subject to

$e_{h}(k)=h(k)-s p h$

$e_{c}(k)=c(k)-s p c$

\section{Simulation}

To test the controller, we run a simulation for a test ditch with set points for water level (sph) and concentration (spc) of $-0.41 \mathrm{~m}$ and $550 \mathrm{~g} / \mathrm{m}^{3}$, respectively. There are two known changes in the exfiltration concentration (Fig 2.a.) and exfiltration discharge (Fig 2.b.) during the simulation. The controller responds to these known set changes and keeps the water level (Fig 2.d.) around the set point of $-0.41 \mathrm{~m}$ without any violation of the concentration (Fig 2.e.) set point by arranging the flushing and outflow discharges (Fig 2.c.).
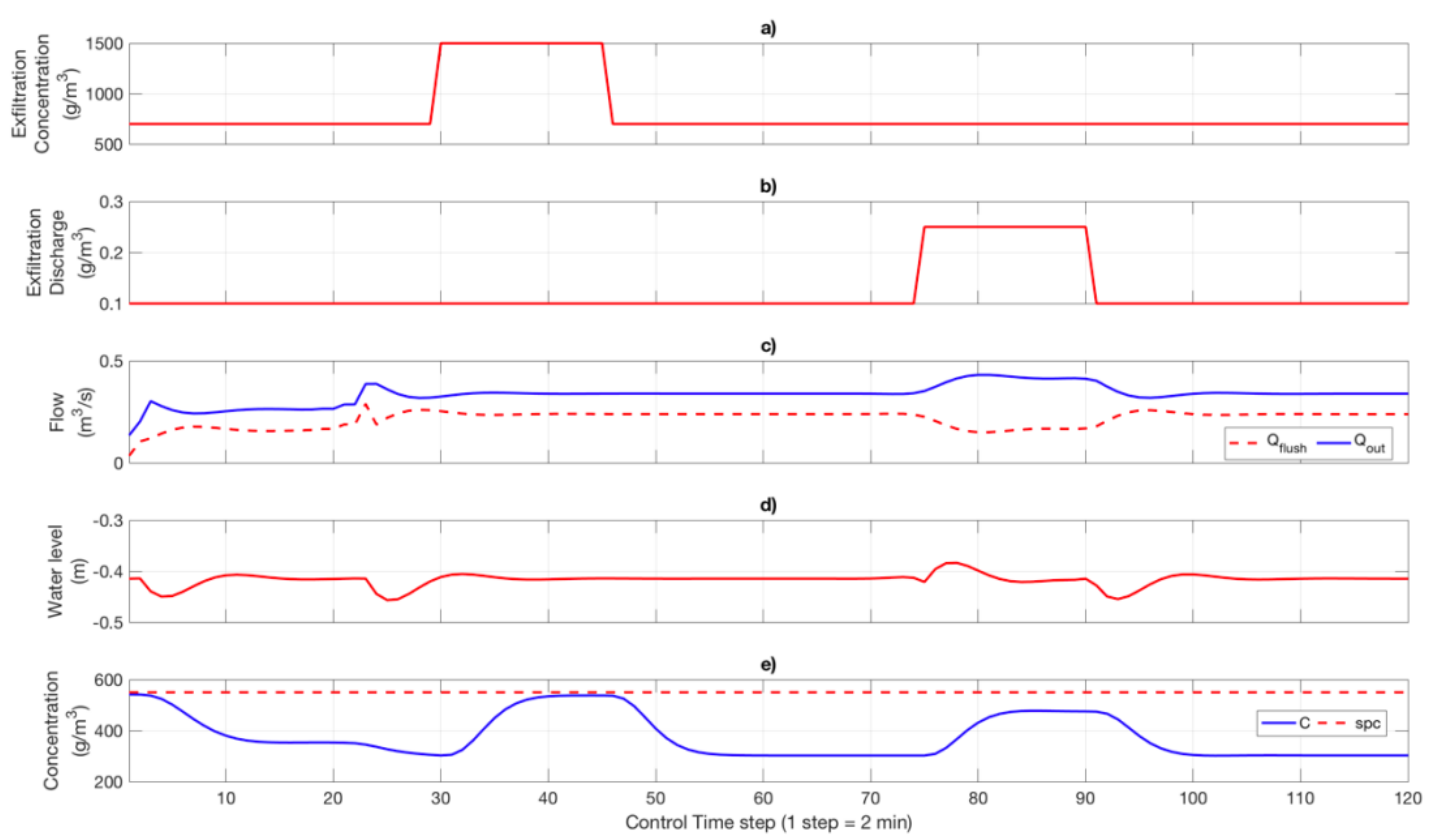

Figure 2 Results of the simulation. a) Exfiltration concentration, b) Exfiltration discharge, c) Controlled flushing discharge (dashed line) and outflow discharge, d) Water level, e) Concentration (dashed line shows the set point for concentration) 


\section{Conclusion}

Applying a MPC scheme to increase the efficiency of operations of polders is possible. In this paper, we have presented a MPC scheme to control salinity and water level for a polder ditch. This is an ongoing work that we think control of a hypothetical test case will be possible with this scheme. The necessary steps to apply the scheme and the conceptual idea are given and flowed by a simple simulation with known changes in the exfiltration discharge and concentration. The results show that with the proposed method, controlling the water level and salinity is possible with the proposed method.

\section{References}

J.R. Delsman, Saline groundwater-Surface water interaction in coastal lowlands, IOS Press, Inc., Amsterdam, 2015. doi:10.3233/978-1-61499-518-0-i.

F. Klijn, E. Van Velsen, J. Ter Maat, J.C. Hunink, Zoetwatervoorziening in Nederland [in Dutch], (2012).

G.H.P. Oude Essink, E.S. Van Baaren, P.G.B. De Louw, Effects of climate change on coastal groundwater systems: A modeling study in the Netherlands, Water Resour. Res. 46 (2010) 116. doi:10.1029/2009WR008719.

M. Xu, P.J. Van Overloop, N.C. Van De Giesen, G.S. Stelling, Real-time control of combined surface water quantity and quality: Polder flushing, Water Sci. Technol. 61 (2010) 869-878. doi:10.2166/wst.2010.847.

M. Xu, P.J. van Overloop, N.C. van de Giesen, Model reduction in model predictive control of combined water quantity and quality in open channels, Environ. Model. Softw. 42 (2013) 7287. doi:10.1016/j.envsoft.2012.12.008.

B.E. Aydin, M. Rutten, G.H.P.O. Essink, J. Delsman, Polder Flushing: Model Predictive Control of Flushing Operations to Effective and Real Time Control of Salinity in Polders, Procedia Eng. 154 (2016) 94-98. doi:10.1016/j.proeng.2016.07.424.

C. Camacho, E. F.; Bordons, Model Predictive Control, 2nd ed., Springer, London, 2007. doi:10.1007/978-0-85729-398-5. 